\title{
REFERENSI ENDOFORA DALAM NOVEL LAGUNA KARYA IWOK ABQARY DAN IMPLIKASINYA BAGI PEMBELAJARAN BAHASA INDONESIA DI SMA
}

\author{
Asep Muhyidin \\ Universitas Sultan Ageng Tirtayasa \\ email: muhyidin21@untirta.ac.id
}

\begin{abstract}
Abstrak
Keterkaitan antarkalimat dan antarparagraf dalam sebuah tuturan merupakan syarat dalam pembentukan sebuah wacana karena dengan keterkaitan yang padu wacana menjadi utuh. Penelitian ini bertujuan mendeskripsikan penggunaan referensi endofora dalam novel Laguna karya Iwok Abqary. Data yang diambil adalah satuan lingual berupa kalimat yang memiliki penanda referensi endofora yang bersifat anaforis dan kataforis. Sumber data dalam penelitian ini berupa paragraf-paragraf yang terdapat pada novel. Metode yang digunakan untuk mengumpulkan data pada penelitian ini adalah simak. Analisis data dalam penelitian ini menggunakan metode agih. Hasil penelitian menunjukkan adanya 401 pemarkah referensi anaforis dan 71 pemarkah buah referensi kataforis. Sebagian besar pemarkah referensi endofora berupa pronomina persona. Hasil penelitian dapat dimanfaatkan dalam pembelajaran bahasa Indonesia di SMA. Untuk itu, guru harus mampu membuat skenario pembelajaran yang menjadikan siswa dapat memahami penggunaan referensi endofora dalam paragraf, sehingga pada akhirnya siswa memahami isi dan amanat yang terkandung dalam novel tersebut.
\end{abstract}

Kata Kunci: referensi endofora, novel, pembelajaran bahasa Indonesia

\section{ENDOPHORIC REFERENCES IN IWOK ABQARY' NOVEL LAGUNA AND THE IMPLICATIONS FOR THE INDONESIAN LANGUAGE LEARNING AT SENIOR HIGH SCHOOLS}

\begin{abstract}
Relationships between sentences and paragraphs in a speech are a requirement in the formation of a discourse because through such relationships a discourse becomes coherent. This study aims to describe the use of endophoric references in Iwok Abqary' novel Laguna. The data were lingual units in the form of sentences with endophoric reference markers anaphoric and cataphoric in nature. The data sources were paragraphs in the novel. The data were collected through reading. They were analyzed by the distributive method. The findings show that there are 401 anaphoric reference markers and 71 cataphoric reference markers. Most endophoric reference markers are personal pronouns. The findings can be utilized in the Indonesian language learningat senior high schools. For this reason, teachers must be able to create learning scenarios that make students understand the use of endophoric references in paragraphs in order that they understand the contents and messages in the novel.
\end{abstract}

Keywords: endophoric references, novel, Indonesian language learning 


\section{PENDAHULUAN}

Dalam setiap jenjang pendidikan diharapkan siswa mampu mengenali berbagai jenis wacana (Emilia dkk., 2018). Wacana dari segi bentuknya dapat direalisasikan dalam bentuk karangan yang berupa novel, buku, seri ensiklopedi, dan sebagainya dalam kata, kalimat, atau paragraf, yang membawa amanat yang lengkap (Kridalaksana: 2001: 231). Novel merupakan salah satu bentuk wacana tulis. Dari segi panjang cerita, novel lebih panjang daripada cerita pendek meskipun keduanya merupakan karya sastra prosa. Sebagai karya sastra prosa, wacana dalam novel harus disusun berdasarkan unsur-unsur pembangunnya supaya tercipta karya sastra prosa yang berkualitas.

Dalam sebuah novel hubungan antarkalimat harus selalu diperhatikan untuk memelihara keterkaitan dan keruntutan antarkalimat. Keterkaitan yang padu antarkalimat dan antarparagraf dalam sebuah novel merupakan syarat penting dalam pembentukan sebuah wacana karena dengan keterkaitan yang padu wacana menjadi utuh. Keterkaitan antarkalimat pengembang topik secara semantis disebut koherensi sedangkan keterkaitan secara leksikal dan gramatikal disebut kohesi. Sarana kohesi dan sarana koherensi dapat digunakan sebagai penghubung antarkalimat dan antarparagraf. Penggunaan sarana kohesi yang tepat dalam sebuah wacana akan membuat wacana tersebut menjadi koheren (Suwandi, 2016).

Keberadaan wacana dalam teks novel sangat penting karena wacana membantu memberikan penafsiran tentang makna ujaran dalam teks. Di samping itu, novel yang merupakan komunikasi pengarang kepada pembacanya harus mudah dipahami dan dapat dicerna dengan baik. Pengarang menggunakan pemarkah kohesi agar kalimat-kalimat dalam novel menjadilebih bervariasi(Jabeen dkk., 2013). Dalam novel banyak ditemukan pemahaman yang utuh terhadap maksud wacana novel. Oleh karena itu, analisis referensi anafora pada novel Laguna karya Iwok Abqary perlu dilakukan agar dapat memberikan sumbangan pemahaman pembacaan pada novel.

Wacana tidak dapat dilepaskan dari konteks. Konteks wacana terdiri atas berbagai unsur, seperti situasi, pembicara, pendengar, waktu, tempat, adegan, topik, peristiwa, bentuk amanat, kode, dan saluran (Alwi dkk., 2014: 474). Dalam wacana tulis konteks sangat penting untuk diperhatikan karena makna sebuah teks sering ditentukan oleh pengertian yang diberikan oleh teks lain. Selain faktor konteks, wacana juga ditentukan oleh hubungan antarunsur (kohesi). Menurut Halliday dan Hasan (1976: 4) kohesi adalah perangkat sumber kebahasaan yang dimiliki setiap bahasa sebagai bagian teks dengan bagian lainnya. Kohesi yang baik menyiratkan koherensi, yaitu hubungan semantis yang mendasari wacana itu. Dalam teks tertulis, referensi sebuah kata atau kalimat ditentukan oleh penulis. Referensi menurut Halliday dan Hasan (1976: 38) merupakan hubungan antara unsur di dalam teks dengan unsur lainnya yang memberikan penjelasan di dalam acuannya.

Penelitian ini memilih novel Laguna karya Iwok Abqary karena novel ini berupa novel yang bersifat naratif yang kaitan antarkalimat terjalin sangat erat dengan ditandai alat kohesi yang padu. 
Novel ini menceritakan tentang keindahan Blue Langoon Resort yang menjadi tempat pelarian Arneta (Neta) untuk menyembuhkan luka hatinya. Novel ini bertemakan percintaan anak muda zaman sekarang terdiri atas 232 halaman dan diterbitkan oleh Gramedia pada tahun 2014.

Dalam struktur wacana novel, aspek kohesi dan koherensi sangat diperlukan keberadaannya untuk menata pertalian antara proposisi yang satu dengan yang lainnya untuk mendapatkan keutuhan. Keutuhan yang koheren tersebut dijabarkan oleh adanya hubungan-hubungan makna yang terjadi antarunsur secara semantis. Pada dasarnya wacana yang utuh adalah wacana yang kohesif dan koheren. Keutuhan wacana merupakan faktor yang menentukan kekuatan bahasa. Salah satu aspek kohesi gramatikal adalah referensi. Halliday dan Hasan (1976: 33; Bloor \& Bloor, 2013: 27) membagi referensi berdasarkan acuannya menjadi dua macam yaitu referensi endofora dan referensi eksofora. Referensi endofora atau referensi tekstual adalah apabila yang diacu atau yang memberikan penjelasan informasi itu terletak di dalam teks (Rani, dkk., 2004: 99; Zaimar dan Harahap, 2011: 126). Berdasarkan arah acuannya, referensi endofora dibedakan menjadi dua macam, yaitu 1) referensi anafora, dan 2) referensi katafora (Halliday dan Hassan, 1976: 33). Refensi anafora adalah pengacuan oleh pronomina terhadap anteseden yang mendahuluinya atau terletak di sebelah kiri (to proceeding text). Sebaliknya, referensi katafora adalah pengacuan pronomina terhadap anteseden yang mengikutinya atau terletak di sebelah kanan (to following text).
Referensi endofora, baik yang bersifat anafora maupun katafora biasanya berupa pronomina persona, prononima demonstratif, dan pronomina komparatif (Halliday dan Hasan, 1976: 37). Pronomina persona adalah deiktis yang mengacu pada orang secara bergantiganti bergantung pada "topeng" yang sedang diperankan oleh partisipan wacana (Fillmore dalam Rani dkk., 2004: 100). Pronomina demonstratif adalah kata deiktis yang dipakai untuk menunjuk nomina (Rani dkk., 2004: 102). Prononima komparatif adalah deiktis yang menjadi bandingan bagi antesedennya (Rani dkk., 2004: 104). Referensi anafora dan katafora biasanya terdiri atas pronomina orang ketiga seperti $i a$, dia, mereka, -nya (Trnavac dan Taboada, 2016).

Pengacuan persona merupakan keterkaitan semantik antara satu unsur dari suatu alat kohesi dengan unsur lain yang dirujuknya (Halliday dan Hasan, 1976: 37). Pengacuan persona merujuk pada peserta dan sesuatu yang dibicarakan dalam situasi komunikasi. Berdasarkan perannya, dikenal dengan istilah orang pertama, orang kedua, dan orang ketiga. Orang pertama adalah pembicara (speaker), orang kedua adalah pendengar (addressee) atau yang diajak berbicara, dan orang ketiga adalah peran lain (other roles) atau orang yang sedang dibicarakan. Hal ini sejalan dengan pendapat Sumarlam (2003: 24) bahwa pengacuan persona dapat direalisasikan melalui pronomina persona (kata ganti orang), yang meliputi persona pertama (persona I), kedua (persona II), dan ketiga (persona III), baik tunggal maupun jamak. Pronomina persona I tunggal, II tunggal, III tunggal ada yang berupa bentuk bebas (morfem be- 
bas) dan ada pula yang terikat (morfem terikat). Selanjutnya yang berupa bentuk terikat ada yang melekat di sebelah kiri (lekat kiri) dan ada yang melekat di sebelah kanan (lekat kanan).

Pengacuan demonstratif merupakan pengacuan yang mengacu kepada lokasi atau waktu yang dirujuk secara khusus (Halliday dan Hasan, 1976: 37). Dapat dikatakakan bahwa pengacuan demonstratif merupakan pengacuan kata ganti penunjuk. Kridalaksana (2001:92) membedakan pengacuan demonstratif (kata ganti tunjuk) menjadi dua, yaitu pronomina demonstratif waktu (temporal) dan pronomina demonstratif tempat (lokasional). Pronomina demonstratif waktu meliputi pronomina waktu kini, waktu lampau, waktu yang akan datang, dan waktu netral. Sementara itu, pronomina demonstratif tempat meliputi tempat atau lokasi yang dekat dengan pembicara (sini, ini), agak jauh dengan pembicara (situ, itu), jauh dengan pembicara (sana), dan menunjuk tempat secara eksplisit.

Referensi komparatif adalah keterkaitan semantis antara satu unsur dengan yang lain yang dirujuknya serta yang digunakan untuk membandingkan dua hal. Referensi komparatif merupakan referensi tidak langsung berdasarkan identitas atau kesamaan (Halliday dan Hasan, 1976: 37). Referensi komparatif dalam bahasa Indonesia menurut Hartono (2000:151) berkenaan dengan perbandingan dua maujud atau lebih, meliputi tingkat kualitas atau intensitasnya dapat setara atau tidak setara. Tingkat setara disebut tingkat ekuatif, tingkat yang tidak setara dibagi menjadi dua yaitu tingkat komparatif dan tingkat superlatif. Tingkat ekuatif mengacu ke kadar kualitas atau intensi- tas yang sama atau mirip. Tingkat komparatif mengacu ke kadar kualitas atau intensitas yang lebih atau yang kurang. Tingkat superlatif mengacu ke kadar kualitas atau intensitas yang paling tinggi di antara adjektiva yang dibandingkan. Hal-hal yang dibandingkan berupa sikap, sifat, watak, perilaku, dan sebagainya. Kata-kata yang biasa digunakan untuk membandingkan, antara lain seperti, bagai, bagaikan, sama dengan, tidak berbeda dengan, persis seperti, dan persis sama dengan.

Beberapa penelitian terdahulu yang relevan dengan penelitian ini dilakukan oleh Fadele dan Kaiser (2014), Sumanti (2015), Trnavac dan Taboada (2016), dan Wiyanti dan Dinihari (2017). Keempat penelitian terdahulu kesemuanya membahas referensi endofora, yang membedakan adalah data penelitian. Fedele dan Kaiser menggunakan data struktur kalimat dalam bahasa Italia yang mengandung referensi anafora dan katafora. Sumanti menggunakan data penelitian berupa satuan lingual berupa kalimat-kalimat pada novel $\mathrm{Su}$ vernova: Akar karya Dee Lestari yang mengadung referensi endofora, baik berupa anafora maupun katafora. Trnavac dan Taboada melakukan penelitian melalui ujaran-ujaran dalam bahasa Inggris yang terdapat dalam Open American National Corpus (OANC) sebagai korpus data utama dan ujaran-ujaran dalam English Broadcast News sebagai korpus data sekunder yang mengandung referensi katafora. Penelitian yang dilakukan oleh Wiyanti dan Dinihari (2017) mengenai aspek anafora dan katafora pada tajuk rencana koran Kompas menemukan bahwa tajuk rencana koran cenderung lebih banyak dan dominan menggunakan aspek ko- 
hesi anafora dan pemarkah pronomina demonstratif dibandingkan aspek kohesi katafora dan pemarkah lainnya. Penelitian ini membahas kohesi gramatikal endofora, baik yang berupa anafora maupun katafora dalam novel.

Berdasarkan latar belakang yang telah diuraikan di atas, fokus penelitian ini adalah penggunaan kohesi gramatikal referensi dalam novel Laguna karya Iwok Abqary. Adapun subfokusnya adalah penggunaan referensi endofora dalam novel Laguna karya Iwok Abqary. Berdasarkan latar belakang, fokus dan subfokus penelitian, dapat dirumuskan permasalahan sebagai berikut: 1) Bagaimana penggunaan referensi endofora anaforis dalam novel Laguna karya Iwok Abqary?; 2) Bagaimana penggunaan referensi endofora kataforis dalam novel Laguna karya Iwok Abqary? dan; 3) Bagaimana implikasinya bagi pembelajaran bahasa Indonesia di SMA?

\section{METODE}

Dalam penelitian ini metode yang digunakan adalah deskriptif kualitatif. Penelitian ini berusaha meneliti dan menyelidiki penggunaan referensi endofora yang digunakan dalam novel Laguna karya Iwok Abqary, kemudian menguraikan implikasinya bagi pembelajaran bahasa Indonesia di SMA. Dalam penelitian ini dideskripsikan sarana penanda referensi endofora dalam wacana tulis berupa novel. Sumber data dalam penelitian ini berupa sumber data tertulis yaitu paragraf-paragraf yang terdapat pada novel. Adapun data yang diambil yaitu satuan lingual berupa kalimat-kalimat yang memiliki penanda referensi endofora yang bersifat anaforis dan kataforis yang terdapat dalam novel.
Pengumpulan data dalam penelitian ini menggunakan metode simak dan catat (Sudaryanto, 2015:133). Metode simak yang digunakan dalam penelitian ini yaitu menyimak tulisan yang ada dalam novel Laguna karya Iwok Abqary. Teknik catat digunakan untuk mencatat data dalam kartu data. Dalam kartu data tersebut terdapat dua bagian, yaitu bagian deskripsi dan bagain refleksi. Bagian deskripsi digunakan untuk mencatat penggalan wacana yang mengandung referensi endofora. Sementara itu, bagian refleksi berisi hasil interpretasi terhadap penggalan wacana yang mengandung referensi endofora tersebut. Langkah-langkah penelitian dalam mengumpulkan data adalah : 1) membaca secara teliti wacana novel; 2) menyimak paragraf demi paragraf untuk menemukan ada tidaknya penanda referensi; 3) menginventarisasi penggalan wacana yang mengandung referensi endofora, baik yang bersifat anaforis maupun kataforis dengan mencatatkannya pada kartu data; dan 4) mengelompokkan penggalan-penggalan wacana tersebut ke dalam klasifikasi penanda referensi endofora, baik yang bersifat anaforis maupun kataforis. Dalam penelitian ini menggunakan validitas semantik yaitu data-data mengenai penanda hubungan antarkalimat dalam wacana dapat dimaknai sesuai dengan konteksnya. Adapun reliabilitasnya menggunakan reliabilitas stabilitas yaitu hasil penelitian menunjuk pada tingkat tidak berubahnya hasil pengukuran yang dilakukan pada waktu yang berbeda dengan cara dilakukan pembacaan berulang-ulang pada waktu yang berbeda untuk membuktikan hasil yang sama terhadap data yang sama. 
Analisis data dalam penelitian ini menggunakan metode agih (Sudaryanto, 2015: 31). Wacana yang dianalisis berupa penggalan-penggalan wacana yang terdiri atas kalimat. Langkah-langkah penelitian dalam menganalisis data adalah: 1) membagi wacana menjadi penggalan wacana; 2) membagi kalimat menjadi beberapa unsur dan mengambil satu unsur yang dianggap sebagai penanda kohesi endofora untuk dianalisis lebih lanjut; 3) menggunakan teknik ganti yaitu dengan mengganti penanda referensi endofora dengan satuan lingual (anteseden) yang dapat diterima (gramatikal); 4) menggunakan teknik baca markah untuk melihat langsung letak anteseden (sebagai penanda) yang diacu oleh pemarkah kohesi, mengarah ke sebelah kiri pemarkah (anafora) atau mengarah ke sebelah kanan pemarkah (katafora); dan 5) menarik inferensi serta simpulan tentang penggunaan refe- rensi endofora, baik yang bersifat anaforis maupun kataforis.

\section{HASIL DAN PEMBAHASAN}

Pada bagian ini akan diuraikan hasil penelitian yang telah dilakukan beserta pembahasaannya.

\section{Referensi Anafora}

Refensi anafora berupa pronomina persona yang ditemukan dalam penelitian ini berjumlah 401 buah. Referensi anaforis adalah satuan lingual tertentu mengacu pada satuan lingual yang lain yang mendahuluinya (Halliday dan Hasan, 1976: 33). Pronomina persona berupa pronomina takrif tunggal dan jamak. Berikut ini adalah contoh data tersebut.

(1) "Nah apa?" Neta memutar bola matanya."Kamu pikir aku suka sama monster itu? Dia pembunuh berdarah dingin! Lelaki itu sudah

\section{Tabel 1. Temuan Referensi Endofora}

\begin{tabular}{|c|c|c|c|c|}
\hline \multirow{2}{*}{ No. } & \multirow{2}{*}{ Klasifikasi } & \multicolumn{2}{|c|}{ Referensi Endofora } & \multirow{2}{*}{ Jumlah } \\
\hline & & Anafora & Katafora & \\
\hline 1. & Pronomina Persona & 401 & 71 & 472 \\
\hline 2. & Pronomina Demonstratif & 9 & 5 & 14 \\
\hline 3. & Pronomina Komparatif & 1 & 0 & 1 \\
\hline & Jumlah & 411 & 76 & 487 \\
\hline
\end{tabular}

Tabel 2. Temuan Referensi Anafora

\begin{tabular}{clc}
\hline A. & \multicolumn{1}{c}{ Pronomina Persona } & Wujud \\
1 & Pertama Tunggal & $-k u$ \\
2 & Kedua Tunggal & $-m u$, Anda \\
3 & Ketiga Tunggal & - nya, beliau, ia, dia \\
4 & Ketiga Jamak & mereka \\
\hline B. & Pronomina Demonstratif & ini, itu \\
1 & Penunjuk Umum & di sini, di sana \\
2 & Penunjuk Tempat & \\
\hline C. & Pronomina Komparatif & seperti \\
1. & Perbandingan Umum
\end{tabular}


Tabel 3. Temuan Referensi Katafora

\begin{tabular}{clc}
\hline A. & Pronomina Persona & Bentuk \\
1. & Pertama Tunggal & saya, aku \\
2. & Pertama Jamak (inklusif) & kita \\
3. & Kedua Tunggal & kamu \\
4. & Ketiga Tunggal & ia, dia, -nya \\
\hline B. & Pronomina Demonstratif & \\
1 & Penunjuk Umum & ini, itu \\
2 & Penunjuk Tempat & di sinilah, di sana \\
\hline
\end{tabular}

menghancurkan semua kesenanganku di sini. (Laguna, 2014: 101)

(2) Ingat, Arneta, kamu datang terlambat tetapi tidak terlihat merasa diburu waktu. Langkahmu terlalu santai seolah jam kerja akan dimulai satu jam lagi. (Laguna, 2014: 23)

(3) Nah, Pak Galang, Neta akan mendampingi Anda berkeliling sekaligus merumuskan rencana kegiatan Anda. (Laguna, 2014: 158)

(4) Neta berjengit, menghentikan langkah di depan lobi secara tiba-tiba. Matanya mendelik ke arah lelaki itu. (Laguna, 2014: 7)

(5) Jabatan Pak Danuwirya sebagai GM harus dicopot karena beliau tak pernah membawa perubahan baik bagi perusahaan. (Laguna, 2014: 9)

(6) Neta diam terkesima. Ia terlalu syok, bahkan tidak bisa marah mendengar selama ini telah dijadikan objek permainan. (Laguna, 2014: 215)

(7) Abangku Decky, tahun depan akan menikah, bakalan semakin jarang mengunjungi Mama. Sekarang dia lebih sering tinggal di apartemennya ketimbang pulang ke sini, apalagi nanti. (Laguna, 2014: 62)

(8) Kebersamaan Neta dan Galang mungkin tidak bias dibantah lagi. Di mata Mark, mereka pasangan yang serasi. (Laguna, 2014: 211)
Pronomina persona pertama tunggal dapat dilihat pada kutipan (1) yaitu unsur - $k u$ mengacu pada anteseden yang lebih dulu dituturkan yaitu Neta. Pronomina tersebut bersifat insani yang memiliki hubungan posesif (kepemilikan). Hal ini sejalan dengan pendapat Halliday dan Hasan (1976: 54) bahwa pronomina persona dalam relasi posesif merupakan pronomina persona yang berelasi dengan kepemilikan, baik enklitik, maupun bebas. Unsur $-k u$ pada kata kesenanganku merupakan sesuatu kepemilikan. Tokoh utama Neta begitu geram terhadap tingkah laku Mark Peter yang telah menghancurkan segala kesenangannya sehingga menganggap tokoh tersebut sebagai monster yang menakutkan.

Pronomina persona kedua tunggal dapat dilihat pada kutipan (2) dan (3) yaitu unsur - $m u$ dan Anda. Unsur - mu pada kata langkahmu mengacu pada tokoh utama Arneta (Neta). Pronomina - mu merupakan pronomina persona kedua tunggal yang meliliki relasi tidak terasingkan (inalienable). Rani dkk. (2004: 101) mengemukakan bahwa pronominal posesif tidak terasingkan merupakan posesif yang selalu melekat pada unsur keseluruhan. Unsur - $m u$ selalu melekat pada kata langkahmu yaitu langkah tokoh utama Arneta. 
Unsur Anda pada kutipan (3) mengacu kepada anteseden Pak Galang. Pronomina Anda digunakan karena tokoh Pak Galang merupakan orang yang dihormati oleh penutur. Dalam budaya bangsa Indonesia, kedudukan dan status sosial penutur dan petutur akan menentukan penggunaan pronomina. Alwi dkk. (2014: 250) mengemukakan bahwa status sosial, baik kedudukan dalam masyarakat maupun badan resmi di suatu instansi ikut mempengaruhi pemakaian pronominal. Pronomina $A n d a$ dalam struktur dan nilai sosial budaya bangsa kita masih terbatas penggunaannya pada masyarakat berpendidikan.

Pronomina persona ketiga tunggal dapat dilihat pada kutipan data (4), (5), (6) dan (7). Kemudian, pronomina persona ketiga jamak terdapat pada kutipan data (8). Pronomina persona ketiga tunggal berbentuk -nya, beliau, ia, dan dia. Kemudian, pronomina persona ketiga jamak yaitu mereka.

Kutipan data (4) pronomina -nya yang diklitikkan pada kata matanya dalam relasi posesif mengacu pada anteseden Neta pada kalimat sebelumnya. Pronomina persona dalam relasi tersebut tergolong tidak terasingkan karena mata Neta melekat pada orangnya.

Kutipan data (5) pronomina persona beliau mengacu kepada Pak Danuwirya. Ungkapan beliau umumnya digunakan dalam bahasa Indonesia untuk menunjukkan kepada orang yang dihormati. Menurut Alwi dkk., (2014: 256) pronomina persona ketiga tunggal beliau dipakai oleh orang yang lebih muda atau berstatus sosial lebih rendah daripada orang yang dibicarakan.

Kutipan data (6) pronomina persona ia mengacu pada tokoh utama yaitu Neta. Lalu, kutipan data (7) pronomina persona dia mengacu pada tokoh Decky. Pada umumnya bentuk pronomina persona $i a$ dan dia berfungsi sama ketika berposisi sebagai subjek. Tetapi bedanya adalah ketika dia dapat berposisi setelah verba atau sebelah kanan dari yang diterangkan, maka hanya bentuk dia yang dapat muncul, sedangkan bentuk ia tidak dapat muncul. Selain itu pula, bentuk ia dapat juga digunakan tidak merujuk pada orang terutama pada jenis tulisan ilmiah. Biasanya dalam tulisan ilmiah bentuk ia merujuk kepada sesuatu yang tunggal yang telah dinyatakan sebelumnya. Hal ini seperti yang dikemukakan oleh Rani dkk. (2004: 101) bahwa pronomina dapat berupa pronomina noninsani yang mengacu bukan kepada manusia.

Referensi anafora berupa pronomina demonstratif ditemukan sebanyak 9 buah. Referensi demonstratif tersebut merupakan kata deiksis yang dipakai untuk menggantikan unsur bahasa. Pronomina demonstratif dalam bahasa Indonesia ada tiga macam, yaitu pronomina penunjuk umum, penunjuk tempat, dan penunjuk ihwal (Alwi dkk., 2014: 260). Dari hasil penelitian, referensi anafora demonstratif yang ditemukan berupa penunjukan umum dan penunjuk tempat. Pronomina ini umumnya mengacu kepada yang bersifat dekat (near) dengan pembicara dan bersifat jauh (far) dari pembicara (Halliday dan Hasan, 1976: 57; Verhaar, 1999: 406; Alwi dkk., 2014: 260). Berikut ini adalah bentuk referensi demonstratif yang bersifat anafora.

(9) Blue Lagoon Resort terhampar di Pulau Bintan Utara. Djatnika Djajakusuma tidak mungkin membuka usaha di sini kalau tidak melihat pe- 
luang keuntungan yang bisa diraupnya. (Laguna, 2014: 30)

(10) Ternyata ruangan itu tidak sepenuhnya kosong. Ada bayangan sesosok tubuh ramping yang melintas di sana, lengkap dengan kemoceng. (Laguna, 2014: 9)

(11) Pulau Penyengat adalah pulau kecil yang terletak sekitar $35 \mathrm{~km}$ dari Bintan dan menjadi salah satu objek wisata andalan provinsi Kepulauan Riau. Pulau ini bahkan sudah didaftarkan ke UNESCO untuk dijadikan salah satu situs warisan dunia. (Laguna, 2014: 11)

(12) Ia sudah menduga pernyataan mundur Neta tadi malam akan menyurutkan hasrat gadis itu untuk tampil atraktif hari ini. (Laguna, 2014: 126)

Kutipan data (9) dapat diketahui terdapat deiksis berupa frasa di sini, deiksis tersebut mengacu pada Pulau Bintan Utara yang terdapat dalam kalimat sebelumnya. Deiksis di sini menyatakan kedekatan antara lokasi dengan situasi pembicaraan. Dengan kata lain, keberadaan deiksis di sini menjadi penanda kohesi gramatikal hubungan antarkalimat dalam wacana. Frasa $d i$ sini dapat dioposisikan dengan frasa $d i$ sana seperti terlihat pada kutipan (10), frasa di sana mengacu kepada ruangan pada kalimat sebelumnya. Frasa di sana menunjukkan lokasi berjauhan dengan situasi pembicaraan. Deiksis menurut Alwi dkk. (2014: 42) adalah gejala semantik yang terdapat pada konstruksi yang hanya dapat ditafsirkan acuannya dengan memperhitungkan situasi pembicaraan.

Kata ini pada kutipan data (11) mengacu pada frasa Pulau Penyengat yang berada pada kalimat sebelumnya. Penggunaan pronomina penunjuk ini dikarenakan acuannya yang dekat dengan pembicara. Jika acuannya agak jauh atau informasi yang sudah disampaikan, maka akan digunakan pronomina penunjuk itu. Hal ini seperti terlihat pada kutipan (11) pronomina penunjuk itu mengacu pada tokoh utama yaitu Neta. Menurut Verhaar (1999: 406) pronomina ini mengacu pada sesuatu yang di tempat penutur, jadi dapat disebut pronomina "persona pertama". Sebaliknya, pronomina itu mengacu pada sesuatu yang bukan tempat penutur, jadi dapat disebut "pronomina ketiga."

Referensi anafora berupa pronomina komparatif hanya ditemukan sebanyak satu buah. Referensi komparatif ini berbeda dengan jenis referensi yang lain, kata-kata dalam referensi komparatif mengacu kepada suatu referen tertentu tidak secara langsung menggantikan referen tersebut, melainkan hanya menerangkan dan membandingkan referen tersebut kepada sesuatu hal (Halliday dan Hasan, 1976: 77). Pengacuan komparatif dikategorikan menjadi dua yaitu pengacuan komparatif yang dinyatakan melalui perbandingan secara umum dan khusus (Halliday dan Hasan, 1976: 37). Perbandingan secara umum meliputi perbandingan identitas, persamaan dan perbedaan. Sedangkan khusus meliputi perbandingan jumlah dan penjelas yang bersifat mendeskripsikan benda. Berikut ini adalah data penggunaan pronominal komparatif yang bersifat anaforis.

(13) Mark mendongak pongah, dia tidak mau mengalah malah berani melawan sorot mata galak Neta yang tertuju ke arahnya. Neta jadi geregetan sendiri. Ternyata ada 
orang yang keras kepala seperti itu, dumelnya sebal. (Laguna, 2014: 107)

Kutipan data (13) merupakan kohesi gramatikal referensi anaforis berupa pengacuan komparatif perbandingan secara umum. Kata seperti pada kutipan data tersebut merujuk kepada sifat Mark yang pongah dan malah berani melawan sorot mata Neta yang telah diinformasikan pada kalimat sebelumnya.

Penelitian pengacuan komparatif pernah dilakukan Riyanto (2015) mengenai bentuk kohesi gramatikal pengacuan komparatif pada media massa cetak. Hasil penelitiannya dapat disimpulkan bahwa ditemukan adanya bentuk kohesi gramatikal pengacuan komparatif (perbandingan) pada media massa cetak. Penelitian tersebut menemukan adanya, 1) kecenderungan penulis menggunakan ungkapan seperti untuk menyampaikan gagasannya, dan 2) adanya ungkapan direktif dari tuturan tersebut.

\section{Referensi Katafora}

Refensi endofora yang bersifat kataforis berupa pronomina persona ditemukan sebanyak 71 buah. Referensi katafora merupakan piranti dalam bahasa untuk membuat rujuk silang dengan hal atau kata terhadap anteseden yang ada di belakangnya (Alwi dkk., 2014: 43). Berikut ini contoh data tersebut.

(14) "Pemilik resort ini ayah saya, Din!" Neta tertawa sumbang, tetap dengan suara sepelan mungkin. (Laguna, 2014: 149)

(15) "Aku tidak mengada-ada tentang event ini. $\boldsymbol{A} \boldsymbol{k u}$ sedang mempersiapkannya," Galang berkilah. (Laguna, 2014: 160)
(16) "Kalau kamu jeli banyak hal yang bisa kamu mainkan tanpa mengurangi profit margin kita," Mark menyodorkan proposal itu lagi ke hadapan Neta. (Laguna, 2014: 42)

(17) Ia hafal benar sosok itu, tanpa sadar memorinya masih merekam kuat bayangan Galang. Tetapi Neta membuang pikiran itu jauhjauh. (Laguna, 2014: 156)

(18) "Tapi dia tidak bisa menghargai apa yang sudah aku lakukan selama ini, Pa. Mark seharusnya bisa lebih menjaga sikap." (Laguna, 2014: 61)

(19) Setelah mengempaskan tubuh di kursi empuknya, Neta segera mencari nomor seseorang di ponsel lalu menekan tombol call secepatnya. (Laguna, 2014: 24)

Kutipan data (14) dan (15) terdapat referensi endofora kataforis berupa pronomina persona pertama tunggal. Pada data kutipan (14) pronominal persona saya mengacu kepada Neta yang berada setelahnya. Kemudian, pada kutipan data (15) pronominal persona aku mengacu kepada tokoh Galang. Pronomina persona saya dan aku merupakan bentuk baku, hanya saja dalam pemakaian mempunyai tempat yang berbeda. Menurut Alwi dkk. (2014: 251) pronomina persona saya adalah bentuk formal yang umumnya dipakai dalam tulisan atau ujaran resmi sedangkan pronomina persona aku lebih banyak dipakai dalam pembicaraan batin dalam situasi yang tidak formal yang menonjolkan keakraban antara penulis dan pembaca.

Pronomina persona kedua tunggal terlihat pada kutipan data (16) yaitu kamu mengacu kepada Neta. Kemudi- 
an, pronomina persona pertama jamak yang sifatnya inklusif kita mengacu kepada Neta dan Mark. Pronomina persona kedua kamu biasanya digunakan oleh: 1) orang yang lebih tua terhadap orang yang lebih muda yang telah dikenal dengan baik dan lama; 2) orang yang status sosialnya lebih tinggi; dan 3) orang yang memiliki hubungan akrab, tanpa memandang umur dan status sosial (Alwi dkk., 2014: 253). Pada novel tersebut, Mark merasa status sosialnya lebih tinggi daripada Neta. Hal ini terjadi karena Mark merupakan orang asing yang dipekerjakan di perusahaan.

Pronomina persona ketiga tunggal terdapat pada kutipan (17), (18), dan (19). Pada kutipan data (17) unsur ia mengacu pada Neta. Kutipan data (18) unsur dia mengacu pada Mark. Kemudian, kutipan data (19) klitika -nya mengacu pada Neta. Unsur pengisi referensi endofora kataforis tersebut terdiri atas pronomina persona, baik orang pertama, kedua, maupun ketiga. Bisa bermakna tunggal dan jamak. Hal ini sejalan dengan pendapat Keraf (1991:62) bahwa referensi orang adalah pengacuan dengan fungsi atau peran di dalam situasi tuturan melalui kategori orang (persona). Dalam bahasa Indonesia, kategori orang termasuk dalam subklasifikasi referensi orang dan terdiri dari orang pertama, kedua, dan ketiga, dengan makna tunggal dan jamak.

Referensi endofora kataforis berupa pronomina demonstratif ditemukan sebanyak 5 buah. Berikut ini bentuk pronomina demonstratif.

(20) Di sinilah Neta terdampar. Dari niat awal untuk melarikan diri dari kekecewaan, akhirnya ia malah menemukan kedamaian. Ia tidak ingin meninggalkan Blue Lagoon. (Laguna, 2014: 31)
(21) Lagi pula kamu ngejar apa sih di sana? Mama bisa menggaji kamu dua kali lipat lebih besar dibanding yang diberikan kantormu itu. (Laguna, 2014: 62)

(22) PT Gading Pratama akan mendapatkan family gathering di resor ini, membawa sekian ratus orang. Kalau Blue Lagoon resort bias memberikan fasilitas dan layanan memuaskan, acara itu akan menjadi ajang promosi yang sangat potensial. (Laguna, 2014: 41)

(23) Lelaki itu menatap Neta. Ekspresi wajahnya datar. Darah di kepala Neta terasa mendidih. Ini sudah jauh melebihi apa yang pernah dibayangkannya. Mark Peter seolah sengaja ingin mempermalukannya di depan umum. (Laguna, 2014: 23)

Kutipan data (20) dapat diketahui terdapat deiksis berupa frasa $d i$ sini, deiksis tersebut mengacu pada tempat yaitu Blue Lagoon yang terdapat dalam kalimat sesudahnya. Deiksis di sini menyatakan kedekatan antara lokasi dengan situasi pembicaraan. Frasa di sini dapat dioposisikan dengan frasa di sana seperti terlihat pada kutipan data (21), frasa di sana mengacu kepada kantormu pada kalimat sesudahnya. Frasa di sana menunjukkan lokasi berjauhan dengan situasi pembicaraan. Frasa di sini dan $d i$ sana merupakan jenis pronominal penunjuk tempat.

Pada kutipan data (22) pronomina penunjuk ini mengacu pada tempat yaitu Blue Lagoon. Penggunaan pronomina penunjuk ini dikarenakan acuannya yang dekat dengan pembicara. Jika acuannya jauh atau informasi yang sudah disampaikan, maka akan 
digunakan pronomina penunjuk itu. Hal ini seperti terlihat pada kutipan (23) pronomina penunjuk itu mengacu pada tokoh Mark Peter. Pronomina ini dan itu merupakan pronominal penunjuk umum. Pronomina penunjuk dalam bahasa Indonesia ada tiga macam, yaitu 1) pronominal penunjuk umum, 2) pronomina penunjuk tempat, dan 3) pronominal penunjuk ihwal (Alwi dkk., 2014: 260)

Pronomina persona adalah pronomina yang dipakai untuk mengacu pada orang. Pronomina persona dapat mengacu pada diri sendiri (pronomina persona pertama), mengacu pada orang yang diajak bicara (pronomina persona kedua), atau mengacu pada orang yang dibicarakan (pronomina persona ketiga). Di antara pronomina itu, ada yang mengacu pada jumlah satu atau lebih dari satu. Ada bentuk yang bersifat eksklusif, ada yang bersifat inklusif, dan ada yang bersifat netral (Alwi dkk., 2014: 249).

Sebagian besar pronomina persona bahasa Indonesia memiliki lebih dari dua wujud. Hal ini disebabkan budaya bangsa Indonesia yang sangat memperhatikan hubungan sosial antarmanusia. Tata krama dalam prilaku kehidupan bermasyarakat menuntuk adanya aturan yang serasi dan sesuai dengan martabat masing-masing penutur. $\mathrm{Me}$ nurut Alwi dkk. (2014: 250) ada tiga parameter yang dipakai sebagai ukuran penggunaan pronomina yaitu: 1) umur; 2) status sosial; dan 3) keakraban.

Dari segi umur, budaya bangsa Indonesia mengharuskan orang yang lebih muda diharapkan menunjukkan rasa hormat kepada orang yang lebih tua. Sebaliknya, orang yang lebih tua diharapkan menunjukkan tenggang rasa kepada yang lebih muda. Unsur timbal balik seperti itu tecermin dalam pemakaian kosakata yang ditemukan dalam penelitian ini, misalnya penggunaan pronomina beliau lebih dipilih daripada pronomina dia.

Status sosial dalam budaya bangsa Indonesia sangat menentukan dalam pemilihan pronomina. Kedudukan sosial di masyarakat ataupun kedudukan di instansi resmi sangat berpengaruh terhadap penggunaan pronomina. Misalnya dalam penelitian ini ditemukan penggunaan pronomina anda digunakan oleh karyawan rendahan kepada tamu yang baru datang. Sebaliknya, pronomina kamu digunakan oleh atasan ketika berbicara dengan bawahannya.

Parameter terakhir, yaitu keakraban dapat, menyilang garis pemisah umur dan status sosial meskipun kadang-kadang hanya dalam situasi tertentu. Ketika dua orang yang sudah akrab sejak lama akan tetap memakai pronomina kamu walaupun di antara mereka berbeda status sosial, misalnya yang satu karyawan dan yang satu lagu adalah pimpinan. Hal ini tergantung pribadi masing-masing dan biasanya ditentukan oleh suasana latar pertemuan tersebut. Dengan demikian, pemakaian pronomina dalam budaya bangsa Indonesia yang masih memegang adat ketimuran sangatlah penting karena pemakaian yang salah dapat menimbulkan hal yang mengganggu keserasian pergaulan.

Mendominasinya pemarkah referensi endofora berupa pronomina persona selain dikarenakan tiga parameter di atas. Hal ini juga dikarenakan pengarang berusaha memperkenalkan karakteristik tokoh agar mudah dikenali oleh pembaca. Pengarang mengguna- 
kan pronomina persona aku jika tokoh tersebut sangat akrab dengan mitra tuturnya. Kemudian, pronomina persona saya digunakan jika tokoh tersebut berhadapan dengan orang yang baru dikenalnya atau jika dalam situasi formal.

Penelitian yang dilakukan oleh Wiyanti dan Dinihari (2017) mengenai aspek anafora dan katafora pada tajuk rencana koran Kompas menemukan bahwa tajuk rencana koran cenderung lebih banyak dan dominan menggunakan aspek kohesi anafora dan pemarkah pronomina demonstratif dibandingkan aspek kohesi katafora dan pemarkah lainnya.

\section{Implikasi Hasil Penelitian bagi Pem- belajaran Bahasa Indonesia di SMA}

Pembelajaran adalah proses pemberian pengetahuan kepada seseorang, sedangkan bahasa adalah sarana yang penting bagi manusia untuk berkomunikasi. Dalam kurikulum 2013 bahasa Indonesia dijadikan penghela ilmu pengetahuan. Oleh karena itu, pembelajaran bahasa Indonesia diselenggarakan dalam rangka pengembangan pengetahuan berbahasa Indonesia agar siswa dapat melakukan kegiatan komunikasi dengan baik dan benar yang meliputi banyak komponen. Komponen itu antara lain tujuan, pembelajaran, metode, sumber belajar, dan evaluasi.

Tujuan belajar adalah hasil yang harus dicapai dalam proses pembelajaran. Pembelajaran bahasa Indonesia bertujuan untuk meningkatkan keterampilan siswa dalam berkomunikasi, maka diperlukan media yang dapat mendukung hal tersebut. Dalam hal ini, salah satu media yang dapat digunakan dalam pembelajaran adalah karya sastra berupa novel. Novel meru- pakan salah satu medium penyampaian pesan kepada pembaca mengenai suatu keadaan, tokoh, atau peristiwa tertentu agar pembaca mampu memahami dan mengambil amanat yang ada di dalamnya. Dengan begitu, diperlukan suatu sarana agar pesan itu dapat disampaikan kepada pembaca dengan lancar. Patriana dkk, (2016) menyatakan bahwa penguasaan terhadap pemarkah wacana membuat tulisan siswa menjadi lebih koheren sehingga menjadi mudah untuk dibaca. Penelitian yang dilakukan oleh peneliti lain (Ali, 2017; Awwad; 2017) menemukan bahwa pemahaman terhadap pemarkah kohesi gramatikal referensi memberikan sumbangan terhadap pemahaman siswa ketika membaca suatu wacana.

Oleh karena itu, hasil penelitian dapat diimplikasikan dalam pembelajaran bahasa Indonesia di SMA. Hal demikian disebabkan karena di dalam Kurikulum 2013 terdapat komponen-komponen pembelajaran yang berkaitan dengan penggunaan kohesi gramatikal referensi untuk mewujudkan kepaduan dan keutuhan paragraf serta penggunaan novel dalam pembelajaran bahasa Indonesia. Adapun, kompetensi dasar yang tercantum dalam Kurikulum 2013 kelas XII menyangkut kompetensi dasar memahami struktur dan kaidah teks cerita fiksi dalam novel baik melalui lisan maupun tulisan.

Berdasarkan penelitian Afrianto (2017) umumnya siswa belum begitu mengenal pemarkah kohesi gramatikal dalam sebuah wacana. Hal ini sangat sesuai jika hasil penelitian ini diintegrasikan dalam pembelajaran bahasa Indonesia di SMA agar para siswa mengenal pemarkah kohesi gramatikal referensi. Dengan demikian, 
Tabel 3. Silabus Pembelajaran

\begin{tabular}{|c|c|c|c|c|c|}
\hline $\begin{array}{c}\text { Kompetensi } \\
\text { Dasar }\end{array}$ & $\begin{array}{l}\text { Materi } \\
\text { Pokok }\end{array}$ & Pembelajaran & Penilaian & $\begin{array}{l}\text { Alokasi } \\
\text { Waktu }\end{array}$ & $\begin{array}{l}\text { Sumber } \\
\text { Belajar }\end{array}$ \\
\hline $\begin{array}{l}3.1 \text { memaha- } \\
\text { mi struktur } \\
\text { dan kaidah } \\
\text { teks novel } \\
\text { melalui lisan } \\
\text { maupun } \\
\text { tulisan }\end{array}$ & $\begin{array}{l}\text { Teks } \\
\text { penggalan } \\
\text { novel Laguna } \\
\text { karya Iwok } \\
\text { Abqary }\end{array}$ & $\begin{array}{l}\text { Mengamati: } \\
\text { 1) Siswa membaca teks } \\
\text { tentang struktur dan } \\
\text { kaidah teks novel. } \\
\text { 2) Siswa mencermati } \\
\text { uraian yang berkaitan } \\
\text { dengan struktur dan } \\
\text { kaidah teks novel. } \\
\text { Mempertanyakan: } \\
\text { 1) Siswa mengajukan } \\
\text { pertanyaan tentang } \\
\text { hal-hal yang } \\
\text { berhubungan dengan } \\
\text { kaidah kebahasaan } \\
\text { teks novel } \\
\text { Mengeksplorasi: } \\
\text { 1) Siswa mencari dari } \\
\text { berbagai sumber } \\
\text { informasi tentang } \\
\text { struktur dan kaidah } \\
\text { teks novel. }\end{array}$ & $\begin{array}{l}\text { Tugas: } \\
\text { 1) Para siswa diminta } \\
\text { berdiskusi untuk } \\
\text { memahami struktur } \\
\text { dan kaidah teks novel. } \\
\text { 2) Secara individual } \\
\text { siswa diminta mencari } \\
\text { referensi endofora } \\
\text { dalam teks novel } \\
\text { Laguna karya Iwok } \\
\text { Abqary } \\
\text { Observasi,: } \\
\text { 1) mengamati kegiatan } \\
\text { siswa dalam proses } \\
\text { mengumpulkan data, } \\
\text { analisis data dan } \\
\text { pembuatan laporan. } \\
\text { Portofolio : } \\
\text { 1) menilai laporan siswa } \\
\text { tentang struktur dan } \\
\text { kaidah teks novel. }\end{array}$ & $\begin{array}{c}2 \text { minggu } X \\
4 \mathrm{JP}\end{array}$ & $\begin{array}{l}\text { 1. Buku } \\
\text { siswa } \\
\text { bahasa } \\
\text { indonesia } \\
\text { SMA } \\
\text { kelas XII } \\
\text { (wajib) } \\
\text { 2. Novel } \\
\text { Laguna } \\
\text { karya } \\
\text { Iwok } \\
\text { Abqary }\end{array}$ \\
\hline & & $\begin{array}{l}\text { Mengasosiasikan: } \\
\text { 1) Siswa mendiskusikan } \\
\text { tentang struktur dan } \\
\text { kaidah teks novel. } \\
\text { 2) Siswa menyimpulkan } \\
\text { hal-hal terpenting } \\
\text { dalam struktur dan } \\
\text { kaidah teks novel. }\end{array}$ & $\begin{array}{l}\text { Tes tertulis: } \\
\text { 1) menilai kemampuan } \\
\text { siswa dalam } \\
\text { memahami teks novel. } \\
\text { 2) menilai kemampuan } \\
\text { siswa dalam } \\
\text { menemukan referensi } \\
\text { endofora dalam teks } \\
\text { novel. }\end{array}$ & & \\
\hline & & $\begin{array}{l}\text { Mengomunikasikan: } \\
\text { 1) Siswa menuliskan } \\
\text { laporan kerja } \\
\text { kelompok tentang } \\
\text { struktur dan kaidah } \\
\text { teks novel. } \\
\text { 2) Siswa membacakan } \\
\text { hasil kerja kelompok } \\
\text { di depan kelas, siswa } \\
\text { lain memberikan } \\
\text { tanggapan. } \\
\text { 3) Siswa } \\
\text { menginterpretasi } \\
\text { makna teks novel baik } \\
\text { secara lisan maupun } \\
\text { tulisan. }\end{array}$ & & & \\
\hline
\end{tabular}

penelitian ini dapat diimplementasikan pada pembelajaran bahasa Indonesia di SMA kelas XII. Untuk itu, guru harus mampu membuat skenario pembelajaran yang menyebabkan siswa dapat memahami dan menggunakan referen- si dalam membuat paragraf menjadi komunikatif, sehingga pada akhirnya siswa memahami isi dan amanat yang terkandung dalam novel tersebut.

Adapun skenario pembelajarannya sebagai berikut. Kegiatan awal: a) Guru 
dan siswa saling memberi salam; b) Guru memberikan apersepsi mengaitkan keadaan sekitar dengan materi pembelajaran; c) Guru memberikan pengantar materi struktur kebahasaan teks novel; d) Guru memberikan pengantar dasar materi kohesi gramatikal referensi endofora sebagai ciri kebahasan teks naratif agar membantu siswa dalam kegiatan inti; dan e) Guru memberikan motivasi belajar kepada siswa. Kemudian, kegiatan inti: a) Guru membuat kelompok belajar yang terdiri atas lima orang; b) Siswa mempelajari dan menalar materi mengenai ciri kebahasaan teks novel dan menghubungkannya dengan kohesi gramatikal referensi endofora; c) Siswa dalam masing-masing kelompok ditugaskan untuk mengidentifikasi penanda referensi endofora yang ada pada teks novel Laguna karya Iwok Abqary tersebut; d) Guru meminta siswa untuk menulis kembali isi novel dalam bentuk paragraf naratif dengan menggunakan penanda kohesi gramatikal referensi endofora untuk menjaga kepaduan wacana; e) Guru meminta siswa untuk menukar hasil kerja antarkelompok; dan f) Masingmasing kelompok ditugasi untuk mengidentifikasi apakah referensi endofora tersebut telah digunakan untuk menjaga kepaduan dan keutuhan paragraf atau tidak. Lalu, kegiatan Akhir: a) Guru bersama-sama siswa menyimpulkan inti dari proses pembelajaran yang telah berlangsung; b) Guru memberikan motivasi dan penghargaan atas kinerja siswa; dan c) Guru memberikan pengayaan berupa tugas membaca, kemudian saling mengucapkan salam dengan siswa.

\section{SIMPULAN}

Referensi endofora yang ditemukan dalam novel Laguna karya Iwok Abqary sebagian besar berupa pronomina persona. Penggunaan pronomina persona oleh pengarang dikarenakan dalam bahasa Indonesia penggunaan pronomina persona tersebut dipengaruhi oleh beberapa parameter, diantaranya adalah 1) umur, 2) status sosial, dan 3) keakraban. Selain itu pula, dengan menggunakan pronomina persona, pengarang berusaha memperkenalkan karakteristik tokoh-tokoh yang terdapat dalam novel tersebut. Hal ini karena novel merupakan sebuah teks naratif yang alur ceritanya tidak akan terjadi apabila tidak terdapat tokoh-tokoh yang diceritakan. Setiap bagian novel tentu akan berkaitan dengan tokohtokoh yang diceritakan, sehingga penulis novel tentu akan banyak menggunakan referensi persona untuk memberikan informasi mengenai tokoh-tokoh tersebut. Hal ini juga menjadikan novel ini mudah dimengerti karena tidak banyak pengulangan kata sehingga dialogdialog yang digunakan menjadi singkat, padat, dan jelas.

Hasil penelitian dapat diimplikasikan dalam pembelajaran bahasa Indonesia di SMA. Hal demikian disebabkan karena di dalam Kurikulum 2013 terdapat komponen-komponen pembelajaran yang berkaitan dengan penggunaan kohesi gramatikal referensi untuk mewujudkan kepaduan dan keutuhan paragraf serta penggunaan novel dalam pembelajaran bahasa Indonesia. Untuk itu, guru harus mampu membuat skenario pembelajaran yang menyebabkan siswa dapat memahami dan menggunakan referensi dalam membuat paragraf menjadi komunikatif. 


\section{UCAPAN TERIMA KASIH}

Penulis menyampaikan terima kasih kepada Rektor dan Dekan FKIP Universitas Sultan Ageng Tirtayasa yang berkenan mengizinkan dan memberi kesempatan penulis untuk melakukan penelitian ini. Ucapan terima kasih juga disampaikan kepada para kolega yang telah memberikan masukan guna mempertajam hasil analisis serta telah membantu dalam penelusuran teori relevan dengan penelitian ini. Artikel ini disarikan dari hasil penelitian mandiri yang dilaksanakan pada bulan Juli sampai bulan Desember 2017.

\section{DAFTAR PUSTAKA}

Afrianto. 2017. Grammatical Cohesion in Student Writings: A Case at Universitas Teknokrat Indonesia. Leksema: Jurnal Bahasa dan Sastra, Vol.2, No. 2, pp. 97-112.

Ali, M.E.E. 2017. The Role of the Anaphoric Referential Relations in Facilitating Reading. International Journal of Education and Research, Vol. 5 No. 2, pp.173-180.

Alwi, H. 2014. Tata Bahasa Baku Bahasa Indonesia. Jakarta: Balai Pustaka.

Awwad, M. 2017. "Exophoric and Endophoric Awareness." Arab World English Journal, Vol. 8, No. 3, pp. 28-45.

Bloor, T. dan M. Bloor. 2013. The Functional Analysis of English: A Hallidayan Approach (3rd ed.). London: Routledge.

Emilia, E. dkk. 2018. An Analysis of Cohesion of Exposition Texts: An Indonesian Context. Indonesian Journal of Applied Linguistics, Vol. 7, No. 3, pp. 515-523.

Fedele, E. dan Elsi K. 2014. Looking Back and Looking Forward: Ana- phora and Cataphora in Italian. Proceeding of the 37th Annual Penn Linguistics Conference, Vol.20 (1), pp. 81-90.

Halliday, M. A. K. dan Ruqaiya Hasan. 1976. Cohesion in English. London: Longman Group Ltd.

Hartono, B. 2000. Kajian Wacana Bahasa Indonesia. Semarang: FBS Unnes.

Jabeen, I. dkk. 2013. "Elipsis, Reference, and Subtitution as Cohesive Device The Bear by Anton Chekhov." Academic Research International, Vol. 4, No. 6, pp. 123-131.

Keraf, G. 1991. Narasi dan Argumentasi. Jakarta: Gramedia.

Kridalaksana, H. 2001. Kamus Linguistik. Jakarta: Gramedia Pustaka Utama.

Rani, A. dkk. 2004. Analisis Wacana Sebuah Kajian Bahasa dalam Pemakaian. Malang: Bayumedia.

Riyanto, S. 2015. Bentuk Pengacuan dalam Wacana Media Massa Cetak. Jurnal Penelitian Humaniora, Vol.16, No. 2, hal. 70-80.

Patriana, A. W, dkk. 2017. Students' Ability in Using Discourse Markes to Build Coherence in Compositions. TEFLIN Journal, Vol. 27, No. 2, pp. 203-216.

Sudaryanto. 2015. Metode dan Aneka Teknik Analisis Bahasa. Yogyakarta: Sanata Dharma University Press.

Sumanti. 2015. Analisis Wacana Novel Supernova: Akar Karya Dee Lestari (Sebuah Tinjauan Referensi). Journal Indonesian Language Education and Literature, Vol. 1, No. 1, hal. 17-28.

Sumarlam, dkk. 2003. Teori dan Praktik Analisis Wacana. Surakarta: Pustaka Cakra. 
Suwandi. 2016. Coherence and Cohesion: An Analysis of The Final Project Abstracts of The Undergraduate Students of PGRI Semarang. Indonesian Journal of Applied Linguistics, Vol. 5, No. 2, pp. 253-261.

Trnavac, R. dan Maite Taboada. 2016. Cataphora, backgrounding, and accessibility in discourse. Journal of Pragmatics Vol. 9, No.3, pp. 68-84.
Verhaar, J.W.M. 1999. Asas-asas Linguitik Umum. Yogyakarta: Universitas Gadjah Mada Press.

Wiyanti, E. dan Yulian Dinihari. 2017. Analisis Kohesi Anafora dan Katafora pada Tajuk Rencana Koran Kompas. Jurnal Bahastra, Vol. 37, No. 1, hal. 9-23.

Zaimar, Okke KS dan Ayu B. Harahap. 2011. Telaah Wacana Teori dan Penerapannya. Depok: Komodo Books. 